\title{
FACTORS CONTROLLING THE LIFE-SPAN OF THE CORPORA LUTEA IN THE PSEUDOPREGNANT RABBIT
}

\author{
R. S. SCOTT AND P. I. C. RENNIE \\ Department of Anatomy, Otago University Medical School, \\ Dunedin, New Zealand
}

(Received 29th December 1969)

\begin{abstract}
Summary. The life-span of corpora lutea (CL) of varying ages within the one rabbit was studied by an experimental procedure in which 2-dayold cL removed from donor rabbits were transferred beneath the kidney capsule of recipient rabbits. Within oestrous recipients, the CL were found to have a total life-span of approximately 17 days, which was similar to that of ovarian CL in the pseudopregnant rabbit. When the CL were transferred into 12-day pseudopregnant rabbits, their life-span was reduced to approximately 11 days and both the ovarian and transferred $\mathrm{CL}$ regressed at approximately the same time. It was suggested that a uterine factor may have caused the early regression of the transferred CL since hysterectomy at the time of transfer prolonged the life-span of each set of CL to approximately 23 to 27 days. In these animals, the GL regressed asynchronously.

Prostaglandin $\mathrm{F}_{2} \alpha$ caused early regression of the ovarian GL when given to hysterectomized rabbits.
\end{abstract}

\section{INTRODUGTION}

The factors controlling the life-span of corpora lutea (CL) in the non-pregnant sheep, pig and rabbit have been studied experimentally by inducing a second set of CL in the presence of existing (older) CL. In the rabbit, however, the experimental findings appear to differ from those in the other two species.

Stormshak \& Casida (1964) gave single intravenous (i.v.) doses of either HCG (200 i.u.) or LH ( 5 to $2000 \mu \mathrm{g}$ ) to pseudopregnant rabbits and found that the former hormone always resulted in new ovulation sites and caused regression of the original CL, whereas the effect of $\mathrm{LH}$ was dose-dependent. Doses of $15 \mu \mathrm{g}$ and higher caused ovulation and luteal regression, while doses of 5 and $10 \mu \mathrm{g}$ failed to cause luteal regression and ovulation was seen only in some of the rabbits. This luteolytic effect of $\mathrm{LH}$ and $\mathrm{HCG}_{\mathrm{C}}$ was probably due to a relative lack of oestrogen following the new ovulation, since Spies, Coon \& Gier (1966) prevented luteal regression following 100 i.u. HCG given i.v. on Day 7 with $1 \mathrm{mg}$ oestrone administered on Days 5 to 8 following the initial ovulation. In these 
experiments, Spies et al. (1966) found the life-span of the induced cL was similar to that in normal pseudopregnancy, i.e. 17 to 20 days.

In sheep, CL induced with ovine pituitary extracts given on Days 3, 7 and 11 of the cycle regressed synchronously with the naturally formed $\mathrm{cL}$ and failed to cause any extension of the oestrous cycle (Inskeep, Oloufa, Pope \& Casida, 1963).

In pigs, GL induced either on Days 7 to 15 with FSH, or on Days 11 to 14 with PMSG followed by HCG, caused prolongation of the oestrous cycle (Neill \& Day, 1964). However, Caldwell, Moor, Wilmut, Polge \& Rowson (1969) showed that GL induced on Day 6 of the cycle regressed with the naturally formed CL towards the end of the cycle.

In the pig and sheep therefore, it would appear that cyclic cL do not have a predetermined life-span, and that there is some factor external to the CL which brings about their regression at the end of the cycle.

The results of the present experiments indicate that luteolysis of the CL of the non-pregnant rabbit is also due to an external factor which is probably of uterine origin. In these experiments, the necessity to induce a second ovulation was avoided by transferring 2-day-old cL beneath the kidney capsule of 12-day pseudopregnant recipient rabbits.

\section{MATERIALS AND METHODS}

Sexually mature, New Zealand White rabbits, 12 to 18 months old and weighing 2 to $3 \mathrm{~kg}$ were assigned at random to each experimental group over the course of the study. The animals were kept isolated in individual cages in a room in which the temperature was maintained between $70^{\circ} \mathrm{F}$ and $80^{\circ} \mathrm{F}$ and in which the light was turned off automatically between 20.00 hours and 06.00 hours. The rabbits were fed on mash (consisting of $31 \%$ bran, $23 \%$ pollard, $33 \%$ whole wheat, $4 \%$ maize meal, $8 \%$ meat meal, $1 \%$ salt and vitamins) with a constant supply of water, the diet being supplemented twice weekly with green vegetables.

All operations were performed at about midday. The rabbits were anaesthetized with a solution of pentobarbitone sodium (Nembutal, Abbott) which was diluted with water and injected into the marginal ear vein in amounts of $40 \mathrm{mg} / \mathrm{kg}$ of body weight. The lower abdomen was shaved and then opened through a mid-line incision, care being taken to avoid damaging mammary tissue.

\section{Induction of pseudopregnancy}

Pseudopregnancy was induced in all non-donor experimental animals with an i.v. dose of 50 i.u. of human chorionic gonadotrophin (Pregnyl, Organon), whereas the donor rabbits received 75 i.u. of Pregnyl on the 3rd or 4th day following a single subcutaneous (s.c.) injection of 75 i.u. of serum gonadotrophin (Gestyl, Organon). These hormones were given at 09.00 hours and the ensuing pseudopregnancy was dated from the time of injection, the succeeding $24 \mathrm{hr}$ being taken as Day 1.

\section{Transfer of corpora lutea}

The experimental procedure for the transfer of cL has been described pre- 
viously by Rennie (1968a) : cL (between nine and twelve) removed from donor rabbits 48 to $52 \mathrm{hr}$ after hormone injection were transferred beneath the left kidney capsule of the recipient rabbits.

\section{Hysterectomy}

Hysterectomy was performed through a mid-ventral incision. Ligatures were placed around the utero-tubal junction and round the blood vessels in the broad ligament passing to the uterus. The vagina was severed just distal to the cervices and sutured with nylon thread; the uterus was then completely removed by cutting on the uterine side of the ligatures. Blood loss was minimal and no uterine fragments were visible at autopsy.

Following the operation, $0.25 \mathrm{~g}$ of sulphamerazine was injected s.c. as a suspension in water.

All tissues taken at autopsy were fixed in Bouin's fluid, sectioned at $8 \mu$ and stained with haematoxylin and chromotrope-2R. A torsion balance (accuracy $0 \cdot 1 \mathrm{mg}$ ) was used to weigh ovaries and CL.

\section{Experiment 1. Normal pseudopregnancy}

A total of twelve rabbits was killed 12, 17, 19, 21 or 23 days after the induction of pseudopregnancy. The ovaries were removed and weighed, and a biopsy of the uterus and vagina was taken. One ovary was set aside for serial sectioning and from the other, the CL were removed and weighed.

\section{Experiment 2. Luteal transfer into oestrous rabbits}

Two-day-old corpora lutea were transferred into twelve oestrous rabbits whose ovaries were devoid of any visible luteal tissue. At the time of transfer, the largest follicles were counted and measured with a vernier caliper and in some, a biopsy of the uterus was taken. The animals were killed at 2-day intervals from 9 to 19 days later (i.e. the luteal cells were between 11 and 21 days old), at which time the graft beneath the kidney capsule was removed, a biopsy of the uterus and vagina was taken and the follicles in the ovaries were again measured.

\section{Experiment 3. Luteal transfer into pseudopregnant rabbits}

Corpora lutea were transferred into twenty-four 12-day pseudopregnant rabbits which were killed 4, 5, 6, 9, 11, 13 and 15 days later (i.e. between 16 and 27 days after the induction of pseudopregnancy). At the time of transfer, a diagrammatic record of the ovarian CL was made so that there would be no doubt as to their future identification, a biopsy of the uterus was taken and the largest follicles were measured. At autopsy, the ovaries were removed and weighed and samples of the uterus and the vagina were taken together with the kidney graft. One of the ovaries was serially sectioned and the cL from the other ovary were shelled out and weighed.

\section{Experiment 4. Effects of hysterectomy on pseudopregnancy}

Six animals were hysterectomized on Day 12 of pseudopregnancy and at the time of operation, the larger follicles were measured and a diagrammatic record of the CL was made. The animals were killed 23, 25 and 27 days following the 
induction of pseudopregnancy and the ovaries were removed and weighed. One ovary was serially sectioned and the CL from the other ovary were weighed.

Experiment 5. Effects of hysterectomy on transferred corpora lutea

Two-day-old cL were transferred into a further six 12-day pseudopregnant rabbits which were hysterectomized at the time of transfer and subsequently killed 13, 16, 20, 23 and 25 days later (i.e. between 25 and 37 days following the induction of pseudopregnancy). At this time, a biopsy of the graft was taken and the ovaries were weighed and set aside for histological examination.

\section{Experiment 6 . Effects of prostaglandin $F_{2} \alpha$ on corpora lutea after hysterectomy}

Two rabbits were hysterectomized on Day 12 of pseudopregnancy. On Days 15 to 18 , the animals received $0.25 \mathrm{mg}$ of prostaglandin $\mathrm{F}_{2} \alpha$ (Upjohn) in saline intraperitoneally twice daily. At autopsy on Day 21 , the ovaries were removed and one was serially sectioned while the CL from the other were weighed.

\section{RESULTS}

The results of the individual experiments are summarized in Text-fig. 1.

The ovarian CL of normal pseudopregnancy reached a maximum size between Days 10 and 14 and thereafter decreased until by Day 17, their average weight was $10.8 \mathrm{mg}$ (Table 1 ). At this time, early histological regressive changes were seen which were clearly evident by Day 2l. They comprised cytoplasmic vacuolation with degeneration and atrophy of the luteal cells, associated with an increase in the intercellular connective tissue. Within any one cL, the degenerative changes did not occur in all luteal cells simultaneously.

TABLE 1

WEIGHTS OF THE GL OF NORMAL PSEUDOPREGNANGY

\begin{tabular}{c|c|c|c}
\hline $\begin{array}{c}\text { Day of autopsy after } \\
\text { the induction of } \\
\text { ovulation }\end{array}$ & $\begin{array}{c}\text { No. of } \\
\text { animals }\end{array}$ & $\begin{array}{c}\text { No. of } \\
\text { CL }\end{array}$ & $\begin{array}{c}\text { Av. wt (mg) of } \\
\text { CL } \pm \text { S.D. }\end{array}$ \\
\hline 12 & 3 & 15 & $19.8 \pm 2.6$ \\
17 & 2 & 8 & $10 \cdot 8 \pm 1.5$ \\
19 & 1 & 4 & $9.6 \pm 1.0$ \\
21 & 4 & 14 & $8.5 \pm 1.9$ \\
23 & 2 & 9 & $7.5 \pm 1.5$ \\
\hline
\end{tabular}

Two-day-old CL transferred into oestrous recipient rabbits showed regressive changes which were similar to those of the ovarian CL of pseudopregnancy. These changes were first seen 15 days after transfer (i.e. when the luteal cells were 17 days old) and were well marked 4 days later.

However, when CL of a similar age were transferred into 12-day pseudopregnant rabbits, they were found to survive for approximately 9 days before showing signs of regression. A total of thirteen rabbits was killed 9 days after transfer and in ten of these, the transferred CL were thought to have become functional as shown by their histology at the time of autopsy. Seven of the ten 
rabbits, and all those killed on subsequent days, showed signs of aL regression which were more advanced in the rabbits killed on the later days. The ovarian aL appeared to be unaffected by the presence of the grafts since neither the

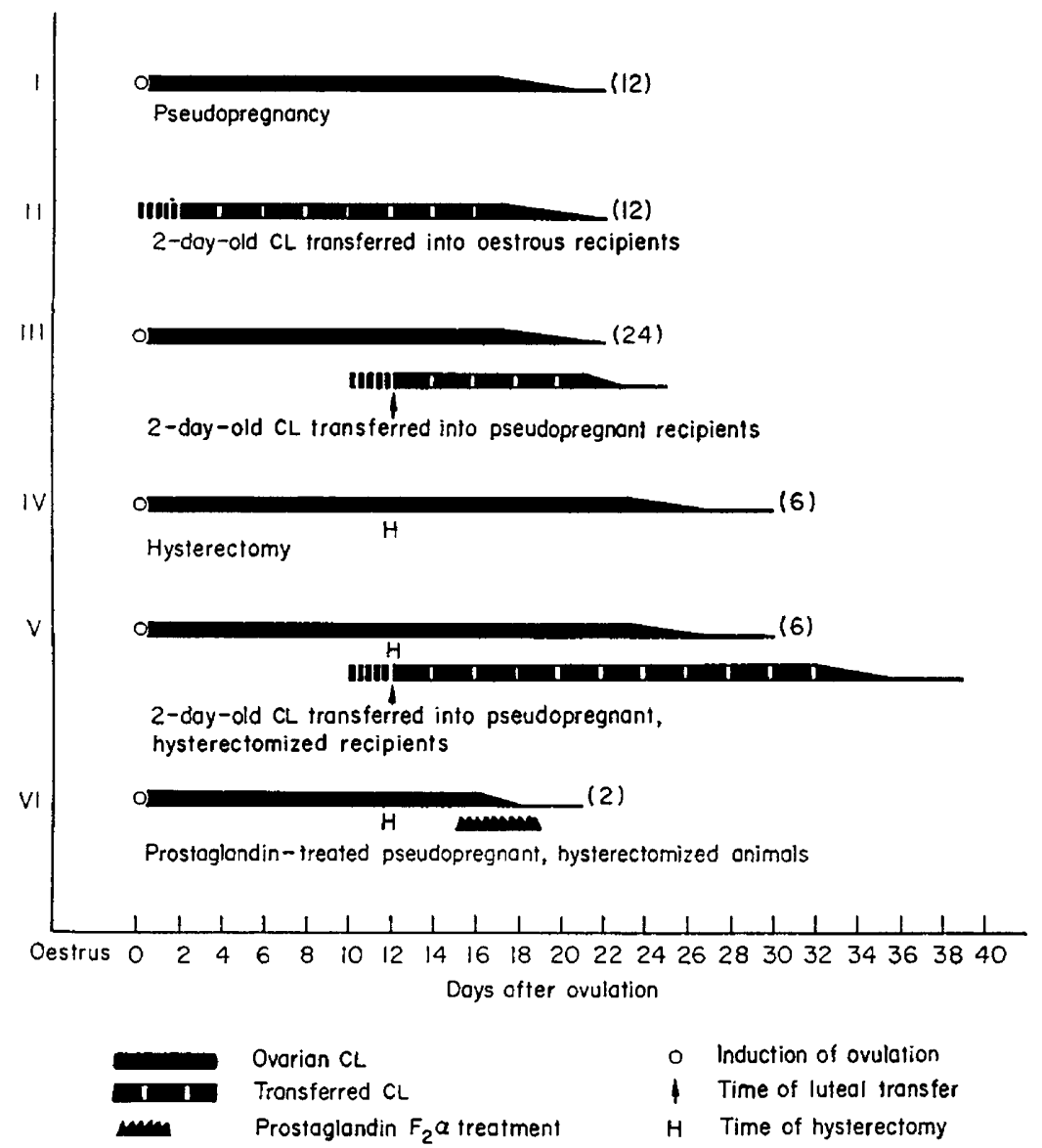

Text-FIG. 1. Summary of results indicating the life-span of the ar in the various experimental groups. Numbers in parentheses indicate the numbers of animals in each group.

\section{TABLE 2}

WEIGHTS OF THE OVARIAN CL FOLLOWING TRANSPLANTATION OF GL BENEATH THE KIDNEY GAPSULE

\begin{tabular}{c|c|c|c}
\hline $\begin{array}{c}\text { Day of autopsy after } \\
\text { the induction of } \\
\text { ovulation }\end{array}$ & $\begin{array}{c}\text { No. of } \\
\text { animals }\end{array}$ & $\begin{array}{c}\text { No. of } \\
\text { ovarian } \\
C L\end{array}$ & $\begin{array}{c}\text { Av. wt (mg) } \\
\text { of ovarian } \\
C L \pm S . D .\end{array}$ \\
\hline 21 & 13 & 32 & $8.2 \pm 1.9$ \\
23 & 4 & 8 & $6.6 \pm 1.2$ \\
25 & 3 & 4 & $6.5 \pm 1.3$ \\
\hline
\end{tabular}

weights of the cL (Table 2) nor their histology varied from those of pseudopregnant control animals.

Hysterectomy on Day 12 of pseudopregnancy prolonged the life-span of both 
the ovarian and transferred CL. In these rabbits, either with or without grafts, the ovarian CL persisted for approximately 23 to 27 days (Table 3) before showing signs of regression. Also, the transferred cL persisted for a similar period, regressing approximately 10 days later than the ovarian CL within the same animal.

Prostaglandin $\mathrm{F}_{2} \alpha$ was found to cause rapid luteal regression. The average weight of fourteen ovarian CL was $4.3 \mathrm{mg}$ (S.D. 1.3) which was approximately a three-fold decrease when compared with intact or hysterectomized rabbits on Day 21 or 23 after the induction of pseudopregnancy.

In all experimental groups, the follicles showed no change in size, number, or degree of atresia when compared with normal rabbits at similar stages of pseudopregnancy, and no changes were evident in the ovarian interstitial cells.

TABLE 3

WEIGHTS OF OVARIAN GL AFTER HYSTERECTOMY ON DAY 12 OF PSEUDOPREGNANCY

\begin{tabular}{c|c|c|c}
\hline $\begin{array}{c}\text { Day of autopsy after } \\
\text { the induction of } \\
\text { ovulation }\end{array}$ & $\begin{array}{c}\text { No. of } \\
\text { animals }\end{array}$ & $\begin{array}{c}\text { No. of } \\
C L\end{array}$ & $\begin{array}{c}A v \cdot w t(m g) \text { of } \\
C L \pm S . D .\end{array}$ \\
\hline 12 & 3 & 15 & $19 \cdot 8 \pm 2 \cdot 6$ \\
23 & 2 & 12 & $12 \cdot 1 \pm 2 \cdot 6$ \\
25 & 2 & 6 & $8 \cdot 6 \pm 2 \cdot 3$ \\
27 & 1 & 3 & $7 \cdot 3 \pm 2 \cdot 3$ \\
\hline
\end{tabular}

\section{DISCUSSION}

These experiments involving transfer of CL into oestrous recipient rabbits are an extension of those previously performed by Rennie (1968a, b), and show that CL beneath the kidney capsule have a life-span which is similar to that of ovarian pseudopregnant cL. This would suggest that the same factor(s) which caused regression of the ovarian CL also led to regression of the transferred CL. In fact, from the present experiments, it appeared that the pseudopregnant CL in the rabbit had a pre- or self-determined life-span. However, this is probably not correct since cL transferred into 12-day pseudopregnant recipients regressed very much earlier than similar grafts in oestrous animals. This strongly suggests the presence of an external luteolytic factor in the rabbit. That this factor is probably of uterine origin is supported by the fact that hysterectomy prolongs the life-span of both the ovarian and transferred $\mathrm{CL}$, each set persisting for approximately 23 to 27 days.

In contradistinction to the intact rabbit, the asynchronous regression of the two sets of $\mathrm{CL}$ in hysterectomized rabbits discounts the possibility of any factor external to the CL causing their regression. Furthermore, that both sets did regress after 23 to 27 days shows that the uterus is not a prerequisite for such regression and that the death of these cL is probably due to ageing.

In the rabbit, it has been shown that luteinizing hormone $(\mathbf{L H})$, in addition to maintaining the cL in hypophysectomized rabbits (Kilpatrick, Armstrong \& 
Greep, 1964), will also cause their regression. Spies, Hilliard \& Sawyer (1968) hypophysectomized rabbits on Day 13 of pseudopregnancy and maintained the histology and physiological activity of the CL with twice-daily injections of $2 \mu \mathrm{g}$ oestradiol benzoate until autopsy on Day 20 . When they gave LH in addition (100 $\mu \mathrm{g}$ s.c. twice daily plus $100 \mu \mathrm{g}$ i.v. once daily), the weights of the GL at Day 20 had decreased from an average of $16.4 \mathrm{mg}$ to $10.3 \mathrm{mg}$. The possibility that LH was the factor which caused regression of the CL in the present experiments was considered, but unless it could be shown to act in conjunction with the uterus, its effect was concluded to be of no consequence.

Hysterectomy prolongs the life-span of the functional CL in the majority of species in the non-pregnant state and, in addition, the uterine horn exerts a local luteolytic effect on the $\mathrm{CL}$ in the ipsilateral ovary (Ginther, 1967). While the present experiments do not eliminate the possibility of a local effect on ovarian CL, they do show that, in the rabbit, a luteolytic effect may be exerted by way of the systemic circulation. In this respect, they agree with the results of Hunter \& Casida (1967), who found that, on Day 26, there was no difference in the weights of the CL in either ovary following unilateral hysterectomy soon after mating. Furthermore, the present findings using transferred CL would establish that luteolysis need not involve neural pathways.

In the rabbit, oestrogen is known to exert a direct luteotrophic effect on the GL and Heckel (1942) has suggested that, rather than producing a hormonal factor, the uterus may cause luteolysis by removing oestrogen from the circulation, thereby diminishing the amount available for CL maintenance. In these experiments, Heckel (1942) showed that increasing amounts of oestrogen would maintain the GL in a more functional state if part of the uterus was removed than if it was intact. This 'oestrogen-sparing' theory has received recent support from the experiments of Spies et al. (1968) in rabbits, but has not gained popularity among those working with other species. It should be pointed out that the results of Heckel (1942) and those of Spies et al. (1968) could equally well be explained by postulating that their manipulations of the uterus caused decreased circulating levels of uterine luteolysin.

Although the presence of a luteolysin can be inferred from early experiments on the effects of hysterectomy in various species, it is only recently that any attempt has been made to isolate such a substance from the uterus. Duby, McDaniel, Spilman \& Black (1969) have shown that bovine endometrial extracts obtained on Days 14 and 16, but not on Days 12 and 18 of the cycle, will cause luteolysis in the hamster; and Caldwell, Moor \& Lawson (1968) have observed a similar effect in this animal using sheep endometrial extracts obtained on Days 14 and 15 of the cycle. Mazer \& Wright (1968), in an attempt to characterize the uterine luteolysin in hamsters, have shown that it is thermolabile and non-dialysable.

Recently, Pharriss \& Wyngarden (1969), using the pseudopregnant rat, and Blatchley \& Donovan (1969), using guinea-pigs, have reported that prostaglandin $\mathrm{F}_{2} \alpha$ caused luteolysis in the hysterectomized animal. In the present experiments, it would appear also that prostaglandin $\mathrm{F}_{2} \alpha$ is exerting a direct luteolytic effect on the GL in the rabbit, but it remains to be proved that prostaglandin is the luteolytic factor produced by the uterus. 


\section{AGKNOWLEDGMENTS}

This work was supported by funds from the Golden Kiwi Lottery and the Medical Research Council of New Zealand. The authors gratefully acknowledge the criticism of the manuscript by Professor W. D. Trotter.

\section{REFERENCES}

Blatchley, F. R. \& Donovan, B. T. (1969) Luteolytic effect of prostaglandin in the guinea-pig. Nature, Lond. 221, 1065.

Galdwell, B. V., Moor, R. M. \& Lawson, R. A. S. (1968) Effects of sheep endometrial grafts and extracts on the length of pseudopregnancy in the hysterectomized hamster. F. Reprod. Fert. 17, 567.

Caldwell, B. V., Moor, R. M., Wilmut, I., Polge, C. \& Rowson, L. E. A. (1969) The relationship between day of formation and functional life span of induced corpora lutea in the pig. F. Reprod. Fert. 18, 107.

Duby, R. T., McDaniel, J. W., Spilman, G. H. \& Black, D. L. (1969) Utero-ovarian relationships in the golden hamster. III. Influence of uterine transplants and extracts on ovarian function following hysterectomy. Acta endocr., Copenh. 60,611.

Ginther, O. J. (1967) Local utero-ovarian relationships. F. Anim. Sci. 26, 578.

HeCkel, G. P. (1942) Estrogen sparing effect of hysterectomy. Surgery Gynec. Obstet. 75, 379.

Hunter, G. A. \& Gasida, L. E. (1967) Absence of local effects of the rabbit uterus on weight of corpus luteum. F. Reprod. Fert. 13, 179.

Inskeep, E. K., Ozoufa, M. M., Pope, A. L. \& GASIDA, L. E. (1963) Functional capabilities of experimentally induced corpora lutea in ewes. F. Anim. Sci. 22, 159.

Kilpatrick, R., Armstrong, D. T. \& Greep, R. O. (1964) Maintenance of the corpus luteum by gonadotrophins in the hypophysectomized rabbit. Endocrinology, 74, 453.

MAZER, R. S. \& WRiGhT, P. A. (1968) A hamster uterine luteolytic extract. Endocrinology, 83, 1065.

NeILl, J. D. \& DAY, B. N. (1964) Relationship of developmental stage to regression of the corpus luteum in swine. Endocrinology, 74, 355.

Pharriss, B. B. \& Wyngarden, L. J. (1969) The effect of prostaglandin $F_{2} \alpha$ on the progestogen content of ovaries from pseudopregnant rats. Proc. Soc. exp. Biol. Med. 130, 92.

RENNIE, P. (1968a) Follicular activity in the maintenance of homotransplanted rabbit corpora lutea. Endocrinology, 83, 314.

RENNIE, P. (1968b) Luteal-hypophyseal interrelationship in the rabbit. Endocrinology, 83, 323.

SPIEs, H. G., Coon, I. L. \& GIER, H. T. (1966) Luteolytic effects of LH and HCG on the corpora lutea of pseudopregnant rabbits. Endocrinology, 78, 67.

Spies, H. G., Hilliard, J. \& Sawyer, G. H. (1968) Pituitary and uterine factors controlling regression of corpora lutea in intact and hypophysectomized rabbits. Endocrinology, 83, 291.

Stormshak, F. \& GAsida, L. E. (1964) Effect of gonadotropins on corpora lutea of pseudopregnant rabbits. Endocrinology, 75, 321. 